\title{
Role of Crop Modeling in scenario Development Analysis and Developing Strategic Recommendation: A Review
}

\author{
Tesfaye Wossen \\ University of Gondar \\ College of Agriculture and Rural Transformation \\ Department of Plant Sciences \\ POBOx: 196 \\ Gondar, Ethiopia
}

\begin{abstract}
:
The agricultural scientists and planners are facing formidable challenges to ensure continued increases in agricultural productivity to meet the food grain requirements of ever increasing population across the globe. Thus, the works on development and use of crop growth models to answer strategic and tactical questions concerning agricultural planning as well as on-farm soil and crop management are essential. Scenarios is a tool for evaluating decisions and testing policy options by indicating possible future situations which indicate the possible effects of decisions. Crop growth models are powerful tools in agricultural decision support at operational, strategic and exploratory levels. Models through the scenario analysis system plays an important role in the interface between farmers, researchers and advisors in participatory research approaches where as agricultural research, model development and testing, and application of mode-based decision support system can be mutually enhancing for better understanding and reaction future situations. This review paper is devoted to crop modeling and scenario development for planning and field level management options in crop production. This helps researchers to understand the role of crop modeling for scenario development to adjust and develop field level recommendation by considering future conditions and developing alternative strategic decisions to reduce the expected negative impact and maximize the benefit.
\end{abstract}

Keywords: Crop modeling, scenario analysis, simulation and strategic management.

\section{Introduction}

The majority of developing countries economy in the globe is depend on limited agricultural resources, which supports an ever increasing population. This makes a continuous unbalanced computation among human being with its limited natural resources, in which it is a scarce resource and need wise utilization with care [20].

According to the report [10], through the continuous interaction among water resources, natural and agricultural ecosystems, with human society in the tropical world there is a significantly effect on both actors and affect the sustainability of the system. These impacts are likely to be particularly severe in developing countries, since the awareness of the people and the level of communication is poor as well as highly dependent on the direct use of local natural resources, and the subsistence farming resulted a widespread poverty risks (CEC, 2007). In line with this, Chuku and Okoye (2009) reported that, Africa is considered vulnerable to climate change, due to a combination of naturally high levels of climate variability, high dependence on climate sensitive activities, such as rainfed agriculture, and minimum economic power and poor institutional setup to cope with, and adapt to, the risks of climate variability and change as well as ecosystem depletion.

Agriculture is the most vulnerable sector in subSaharan Africa by different factors. Since the sector is mainly rainfall based and not supported by technologies, crop yield and productivity per unit area are highly dependent on climate variability (World Bank. 2008). The use of improved agronomic management (use of fertilizer, irrigation, pesticide, combined with modern cultivars) remains low (Dingkuhn et al., 2006). The production and productivity of agricultural products must be 
increased to satisfy the growing demand for food, feed and raw material for industries. While give equal emphasis for natural resource conservation and environmental safety [20].

To balance the need of increase more agricultural products with environmental safety, new agricultural system is needed to supply information to farmers, researchers, policy makers and other concerned decision makers on how to bring sustainable agriculture under the changed climate in to specific location[20]. In most African and Asian countries crop production is conducted business as usual by using conventional way of agronomic research, in which crop production are resulting from arithmetical analysis without connecting to the principal biological or physical principles occupied as a system wise [10].

This type of observation and forecast of growth and maintaining natural ecosystems in response to crop, climate and soil-related factors are highly vital. The relevance of quantitative prediction of complex systems depends on synergy of information through different sectors, and the main approach is all the way through the creation of numerical and reproduction models for mounting scenario analysis. Therefore, this review paper was compiled to show the role of crop modeling for scenario analysis to look alternative possible solution and come up with practical field level recommendation by reviewing relevant papers in the field previously by different scholars.

\section{Crop Modeling and simulation}

The term Model refers a schematic representation of the idea of a system or an operation of imitation or a set of equations, in which it represents the general behaviors of a system. On the other hand it can also express as 'a simplified translation of a component of truth, not a simple copy of the other'. As mentioned by [19], this simplification makes models useful because it offers a comprehensive description of a problem situation.

Modeling is refers the process of using equations or sets of equations derived from the reality of a system, to characterize the nature of a system. In line with this crop models are a schematic representation of the production field by using computer programmers that mimic the growth and development of crops (USDA, 2007). The same report further explain that, crop modeling simulates the characteristics of a actual crop production system by predicting the enlargement of its growth components, such as leaves, roots, stems and grains.
Thus, a crop growth simulation model not only predicts the final output of crop production or harvestable yield, but also consist quantable information about major processes involved in the growth and development of the crop[10]. Based on the definition by [20], simulation is a term defined as "Reproducing the essence or fundamental nature of a system without reproducing the system itself".

Crop modeling began before decades in the 1990s with the aim of rising approaches into crop growth processes by a combination of knowledge expressed in mathematical equations [6]. Similarly Berg and Smith (2005) reported that, the function of crop growth models in decision support defers in accordance with the extent of the decisions made. The same author explained that, modeling can assist to operational and tactical decision making at field level management.

The term 'operational' refers to practical decisions made by respective actors on daily bases based on the real situation happen on the ground [33], while tactical decisions are usually taken at the beginning of a year or growing season by pre-assessing the conditions of future cropping season climatic variability and prepared ourselves to cop up or develop adaptation mechanisms. Different scholars mentioned the application of crop growth models in various applications like; practical decisions have been developed and applied to optimize the proper time of planting and harvest for different crop types [4], its great role for implementing irrigation scheduling [7], and to support site specific crop nutrient management techniques [18].

Due to limited land resources agriculture becomes more intensive; it requires higher demand for improved technologies at higher level of application and control of the environment to enhance productivity per unit area by considering environmental safety as a central point [11]. Intensification with use of intensive inputs ranges from better strategies of soil and water management to cite specific environments, where mostly the atmospheric and soil component of crop production can be adjusted according to the nature of the location and situation. Plant growth and development models hypothesis, should be elaborated to supply a basis for future planning and managing crop production.

At a broader scope crop modeling can be considered as an important means to assist scientists in define and prioritizing research questions. Model also used to estimate the importance and the effect of selected parameters in the field of interest. In this manner 
researchers can scrutinize which factors should be more important in future research focus and enhance the understanding of the system in general. This type of model assisted system has great opportunity to understand the basic interactions in soil-plantatmosphere system and the contribution and limitation of each element involved in the process [11].

The advancement of current computer science and technology brings vast opportunities to consider different factors in crop production as a system not individually and combined them to analyses and interpret the influence of their interactions and possible effects. This pave the way how to quantitatively combine the soil, plant, and climatic systems individually and together to predict crop yield accurately [10]. Today, with the accessibility of low cost and powerful computers and with the emergent recognition of the application of integrated agricultural practices as a system, the current agricultural research and development strategies are developing [16]. Similarly [10] reported that, crop growth modeling, should integrate various disciplines as per the level of current knowledge of plant growth and development like; crop physiology, agrometeorology, soil science and agronomy. One of the powerful computerized decision support systems designed to assist users to combine technical knowledge obtained in crop growth models with their economic implications and environmental impact assessment are currently easily accessed. Decision Support System for Agro- Technology Transfer (DSSAT) [36], is an excellent example of a computer assisted management tool that enables individual farmers to link the biological condition of a crop to the physical circumstances of the farm to obtain targeted outcomes.

\section{Historical development of crop modeling}

Transition from one stage to the next better stage in different sectors is a natural unavoidable process. In the same way the classical research started in the $19^{\text {th }}$ century, shows a progressive change and transform to more sophisticated computer assisted programs now. The development of computer programs and software's help researchers to integrate several components of a system into an inclusive manner which simplify to interpreted the result and implementation. One of the computer assisted program is crop growth simulation models which has been used by many researchers. Jame (1992) reviewed the historical efforts made to quantify the relationships between crop yield and water use from the previous work by using simple water-balance models in the 1960s to the development of crop growth simulation models in the 1980s. In the first time the idea seems untouchable and researchers were not sure whether the complex physical, physiological and morphological processes involved in the growth of a plant could be captured and described mathematically at field condition it may be under controlled environments [10].

In 1982 IBSNAT was the Decision Support System for Agro- Technology Transfer (DSSAT) was developed to help subsistence resource poor farmers in the tropics and sub tropics. As it was explained by [10] one of the primary product of IBSNAT is DSSAT, currently being used as a research and teaching tool. As a research tool its role is to develop recommendations concerning crop management and to explore environmental and sustainability issues.

\subsection{Applications of Crop models}

Crop simulation modeling has been used and being using in several sectors like research, teaching, farm and resource management and policy analysis and future production predictions [10].

According to [20], systems are processes linking the input to the output part and the whole cycles of interacting components. This indicates that, when we change the input component of a system results a changes in other components which is the produces side because of the interaction effect. For example, due to climate change and variability due to global warming creates a change in weather parameters like warm and humid condition, which creates conducive environment for the pathogen to multiply and rapid development of plant disease. This results a loss on crop yield, increase cost of production through spray of chemicals, and causes serious economic loss from individual farmers to the country or regional level in large.

The same author further explains that, the main goals of crop simulation models is to make educated guess for crop production as a function of soil and climatic conditions integrated with agronomic practices and managements. As a basic principle crop models use one or more sets of equations, and compute both rate and state variables over a given time, the time span may be usually from the time of planting in anticipation of harvest maturity or collecting final economic yield.

According to [20], the main goal of the majority application of crop models is to predict economic out-put (final yield). In general the management 
applications of crop simulation models can be defined as: Strategic application: models are run before planting time, Practical application: models are run prior to and during crop growth and Forecasting application: models are run to predict yield both prior to and during crop growth periods.

In USA and Europe farmers, private agencies and government bodies practice crop simulation to a greater extent to formulate decision making. Similarly in Africa climatic conditions these applications have an excellent role to play [32]. The same author explains that, in eastern and horn of African condition, agricultural production is challenged by occurrence of frequent dry spells, scanty and erratic nature in the crop growth period; the on-set of rain varies, in which policy and agricultural scientists fall under pressure and require to set out preparation of contingency plans.

In the majority part of the world especially in Asia and Africa, agriculture is the most important moneymaking activity. Large number of people depends on agriculture for their household income source or to meet their daily dietary needs, such as food. A continues pressure to improve agriculture production happens due to ever increasing in human population. Agriculture is very much influenced by the prevailing weather and climate. This condition demands a systematic appraisal of climatic and soil resources to recast an effective land use plan. More than ever farmers across the globe want access to options such as the management options or new commercial crops [15].

According to [20], the traditional experimentation requires more time and not economical. So, systems analysis and crop simulation modeling plays an important role in promoting in-depth understanding of the system and developing possible options. Through the great advancement in computer technology, DSSAT, has great contribution to reduce substantially the time and cost of field experimentation necessary for adequate evaluation of new cultivars and new management systems.

In a similar manner [24] explains about the software, the package consists of: (1) data base management; (2) crop simulation models; (3) series of utility programs (4) series of weather generation programs and (5) strategy evaluation program to evaluate alternative options like selection of variety, adjusting planting date, determine population density, designing row spacing, identify soil type, determining proper amount, method and time of irrigation, method and dose of fertilizer application, effect of water stress in the vegetative or reproductive stages of development, and determining the final net returns. This is the function of crop modules in scenario development consequently as to formulate strategic field level recommendation.

The agricultural scientists and planners are facing formidable challenges to ensure continued increases in agricultural productivity to achieve the food grain requirements of rapidly increasing population transversely in the world. Conducting field experiment as usual in different location across years is very expensive due to the ever increasing cost of inputs and personal costs. So, it is better to think out of box, not business as usual, develop and implement modern computer assisted crop growth models to formulate strategic and tactical questions regarding crop production planning as well as onfarm level soil and crop management are essential.

\section{Scenario development and application}

\subsection{What is scenario?}

The word "scenario" is derived from the latin scaena, meaning scene [26]. [17]Defines as; scenario is a "story" illustrating visions of possible future or aspects of possible future. It should be well understand that, scenarios are not mean predictions about the future but rather it is similar to develop simulations of some possible futures. Similarly [39] also explained that, scenarios are not a prediction, but are consistent and coherent descriptions of different hypothetical futures that reflect different perspectives on past, present, and future developments which can provide as a fundamental for action. The progress of scenario development starts from World War II in US military planning office and its application extended to the current stage in a wide range of contexts like: from small to medium sized entries, to regional and national insight studies, to environmental assessments for public polices [39]. Similarly, [17], reported that, the scenario method is probably the major concepts and most widely used methods in Foresight.

\subsection{Scenario analysis}

Scenario analysis can be expressed as a process by which possible future events are analyzing by considering alternative possible outcomes (sometimes called "alternative worlds"). Consequently, scenario analysis, which focuses on projection, not to demonstrate the exact picture of the future. On the other way, it presents a number of alternative future developments [3]. As a result, a 
scope of possible future outcomes can be noticeable. In contrast to prognoses, the scenario analysis is not based on extrapolation of the past or the extension of past trends.

It does not rely on historical data and does not expect past observations to remain valid in the future. Instead, it tries to consider possible developments and turning points, which may only be connected to the past. In short, several scenarios are fleshed out in a scenario analysis to show possible future outcomes [34]. Each scenario normally combines optimistic, pessimistic, and more and less probable developments. However, all aspects of scenarios should be plausible. Although highly discussed, experience has shown that around three scenarios are most appropriate for further discussion and selection. More scenarios risks making the analysis overly complicated [2].

At national, regional and local level scenarios can be used to improve planning capacity, to enrich strategic public policy decisions and to guide major capital investments. For example, the development of scenarios allows new insights into the opportunities and risks involved in making decisions about public transport that would have major consequences for the development of a region over the next few decades [17].

\subsection{Importance of Scenario analysis}

Scenario analysis is all about alternative worlds and parallel universes and may include black swans, but stops short of meteor strikes. A key point to remember is that scenario analysis like this is not dependent on past results (in other words, it is not a prognosis); although some people use measures like the standard deviation of past results to provide a framework within which to construct plausible future scenarios [17].

Scenarios began to be used more for exploratory ends than prediction, which raised the possibility of a transformation in the supply chain in business [39]. Scenario planners in general do not start with a narrow focus, doing so increases the chances of missing key determinants of future conditions or events [12]. In exploratory scenario exercises, the process may be as important as the product [39]. As it is stated by [14], the "which World?; scenarios for the $21^{\text {st }}$ century", is a good example of an exploratory exercise investigating possible paths to alternative futures.

According to [17], in pre-policy research, on the other hand, scenarios are used to examine paths to futures that vary according to their desirability. The author expands his explanation; decision support scenarios may be variously described as desirable, optimistic, high-road, or utopia; conventional or middle-of-the-road; and undesirable, pessimistic, low-road, dystopia, or doom scenarios. Similar report made by [13] and [17], pre-policy research scenario may propose concrete options for strategic decision-making and it is more common in prepolicy research scenario exercises to other implicit policy recommendations.

Making sense of the future can challenge mental models and prevailing mind-sets, and can involve learning from the past and investigating fundamental uncertaininties about the future. This type of scenario development is process oriented to promote: learning, communication and improving observational skills [31]. On the other hand, product oriented scenario studies are more concerned with the nature and quality of the output, than the process, as reported by [17]. Identification of driving forces and signs of emerging trends, policy development, and to test policy are the major function of product oriented scenario activities.

Scenario can be used to identify and prioritize the dangers and opportunities in emerging events and processes [22] signs of which are sometimes referred to as "weak signals", "early warning".

Scenarios may also be a tool for evaluating decisions and testing policy options by doing "practice runs" of possible future situations which indicate the possible effects of decisions [42]. Some might say that all scenarios are normative in that they reflect interpretations, values, and the interests of those involved in the scenario exercise. It is nevertheless useful to distinguish between descriptive scenario and those which are explicitly normative [39]. Scenario may also have different views, as stated by [27], scenario looks forwards from the present situation to the future condition or back to the present from a particular future end point can have a bearing on whether it is normative or not.

Based on the nature of the organization and activities under target. The subject covered provides the focus to scenarios. The time scale adopted is one way in which focus is determined, though the perception of time is dependent on context, either short or long scale for a scenario exercise. The time scale is certainly relevant for establishing focus with regards to the issue, the geographical area and the institution the scenario address.

The scenario-based approach to strategic planning builds on the strengths of traditional 
scenario planning, which open and creative approach that considers multiple strategy options and takes multiple perspectives into account. Scenario planning was first introduced in the 1970s at Royal Dutch Shell as a planning technique that replaced traditional forecasting tools [35]. The purpose of scenario planning technique is not to predict exact future, but to develop better strategies by overcoming perceptual biases of managers [28]. [41], reported that, scenario planning is based on the assumption of future developments which are mostly uncertain. The same author stated that, the basic idea of scenario planning is to force managers to acknowledge this uncertainty and to translate it, into thinking in multiple options.

\section{Role of crop modeling}

Crop modeling as a tool in scenario development, has an exploratory uses for decision support to governments or other entities, to develop more targeted innovation or adaptation policies, mainly related to long term assessments [37]. The issue is related to the possibilities of feeding the world population and the effects of climate change on crop production [9]. Now a day, exploratory studies often elaborate on scenarios of different possible socioeconomic futures like climate change which will have different consequences [25].

According to [37], model output can be explained, indicating when to plant, harvest, irrigate, how much to irrigate, and the type of management practices more commonly, output is provided as conditional, what yield can be expected, if certain decisions are taken. Such 'what-if?' models give the user freedom to analysis trade-offs between the biophysical aspects and other dimensions of decision making which are better accounted for by mental models.

Another type of tactical decision support is crop forecasting [20], which emphasizes on the prediction of climatic and related yields over the current season or year. Crop forecasting can be of equal interest to growers, processors and the trading and marketing sectors, as well as o government bodies dealing with trade regulations of food security [40].

Crop modeling has also a great contribution in developing strategic decision making process. As cited by [37], strategic decision making typically refers to assessments of the impact of major changes in land management or substantial investments, introduction of new crops to certain area, use of alterative nutrient management strategies and similar field level recommendations. Many scholars reported to the indirect forms of support of crop modeling to strategic decision making include environmental impact studies regarding nitrate leaching [18], yield benchmarking [13] and calculation of attainable yields in land evaluation studies [36].

Similarly, [14], reported that, yield benchmarking uses to calculate attainable yields as a reference against actual yield. The difference between the two is called the yield gap. [31], also mentioned that, at the farm level, fields with consistently large yield gaps require closer inspection for improved management. Yield gap analysis provides insight to distinguish wel-managed from poorly managed farms. At the country level, governments may address regions with a large yield gap but high attainable yields as those where investments in agricultural development may be the most rewarding [37].

Generally crop growth models are powerful tools in agricultural decision support at operational, strategic and exploratory levels. Models through the scenario analysis system plays an important role in the interface between farmers, researchers and advisors in participatory research approaches where as agricultural research, model development and testing, and application of mode-based decision support system can be mutually enhancing for better understanding and reaction future situations.

As stated by different scholars, scenario is not a forecast, in the sense of a description of a relatively unsurprising projection of the present. Neither is it a vision, that is, a desired future. Scenario is a wellorganized response to the question: 'what can conceivably happen?' or 'what would happen if...?'. Thus it differs from either a forecast or a vision, both of which tend to conceal risks. Scenario, in contrast, makes risk management possible. Scenario planning is, an effective strategic planning tool for medium to long-term planning under uncertain conditions. It helps us to sharpen up strategies, draw up plans for the unexpected and keep a lookout in the right direction and on the right issues.

On the other hand, scenario analysis focus on the link between future studies and strategies used to deal with uncertainties in the future conditions. It is not only a planning instrument, but also an effective tool, which helps to understand the logic of developments, clarity driving forces, key factors, key players and our own potential to exert an influence.

In order to have a workable scenario planning and analysis, crop models have valuable tools that 
scientists can use in testing hypothesis. Models also used to identify the areas where knowledge is lacking, indicating the need for future research activities. In addition, models are being used as decision support systems at the farm level to optimize resource management. By optimizing the inputs such as chemical fertilizers, insecticides, plant growth regulators and harvest aid chemicals, the model not only contribute to increased yield but also help to decrease environmental contamination.

Decision support systems (DSS) like Decision support system for Agro-technology Transfer (DSSAT), are computer systems that assist the user in complex problem solving or decision-making. The system is very helpful in learning more about crop responses to environmental factors, and in complying with governmental regulations. The ability to compare the probable outcomes of different decisions can help a producer being more informed decisions and reduce risk in the face of future uncertainties. Therefore, one of the major reasons to develop and apply crop-model-based decision support system in farm management is to increase profit from the farm and better resource management system.

\section{References}

[1] Aaker, David A. (2001). Strategic Market Management. New York: John Wiley \& Sons. pp. 108

[2] Bea, F.X., Haas, J. (2005). Strategists Management. Stuttgart: Lucius \& Lucius. pp. 279 and 287

[3] Bertrand Hassani, 2016. Scenario Analysis in Risk Management", Published by Springer, 2016

[4] Bezuidenhout, CN., Singels, A., and Hellmann, D., (2002). Whole farm harvesting strategy optimization using the CANEGRO model: A case study for irrigated and dryland sugarcane. Proc S Afr Sug Technol Ass 74: 250-259.

[5] Bishop, P., Hines, A., and Collins, T. (2007), The Current State of Scenario Development: An Overview of Techniques. In: Foresight, 9(1): 5-25.

[6] Bouman, BAM., Van Keulen, h., Van Laar, HH., and Rabbinge, R., (1996). The 'School of de Wit' crop growth simulation models: A pedigree and historical overview. Agric systems 52: 171-198.

[7] Bristow, KL., and Keating, BA., (2003). Systems analysis and modeling in sugar research: reflection on the CRC Sugar experience. Proc Aust Soc Sug Technol 25.

[8] Brockington NR (1979). Computer Modeling in Agriculture. Clarendon Press New York, 156

[9] Checroo-Nayamuth, BF. And Nayamuth ARH. (2001). Climate Change and Sucrose Production in Mauritius. Proc Int Soc Sug Technol Ass, 24 (2): 107-112.

[10] Darko, P.O., Yeboah, S., Addy, S.N.T., Amponsah, S., Danguah, D., (2013). Crop Modeling: A tool for agricultural research. E3 Journal of Agricultural Research and Development. Vol 2(1). pp. 1-6.

[11] Dou rado-Neto, D. A. Teruel, K. Reichardt, D.R. Nielsen, J. A. Frizzone, O.O.S. Bacchi, (1998). Principles of crop modeling and simulation: I. uses of mathematical models in agricultural science. Sci. agric. vol.55.

[12] Duncon, N.E. and P. Wack (1994). "Scenarios Designed to Improve Decision Making", Planning Review, Vol. 22(4), pp. 18-25.

[13] Gertner, R., and M. Knez (2000). "Game theory in reality", Het Financieele Dagblad, pp. 1213.

[14] Hammond, A. (1998). Which World? Scenarios for the $21^{\text {st }}$ Century Global Destinies, Regional Choices, Earth scan Publication Ltd, London.

[15] Hoogenboon, G., 2000. Contribution of agrometerology to the simulation of crop production and its applications. Agril. And For. Meteorol. 103: 137-157.

[16] Jones JW (1993). Decision support systems for agricultural development. Pages 459-471 In: F.W.T. Penning de Vries, P. Teng and $K$. Metsellaar, eds. Systems approaches for agricultural development. Kluwer Academic Publishers, Dordrecht, The Netherlands.

[17] Joseph T., 2006. "Ten Tips for Creating More Powerful Future Stories", FUTURETAKES, the electronic newsletter of the World Future Society's U.S. National Capital Region chapter.

[18] Keating, BA., Verburg, K., Huth, NI., and Robertson, MT., (1997). Nitrogen management in intensive agriculture: Sugarcane in Australia. Intensive Sugarcane production: meeting the Challenges beyond 2000. CAB International, Wallingford, USA, Pp 221242.

[19] Murthy, V.R.K. 2002. Basic Principles of Agricultural Meteorology. Book Syndicate Publishers, Koti, Hyderabad, India.

[20] Murthy, V.R.K. (2003). Crop Growth Modeling and its Application in Agricultural 
Meteorology. Satellite remote Sensing and GIS Application in Agricultural Meteorology. pp 25-26.

[21] Linnemann H, de Hoogh J, Keyzer MA, van Heemst HDJ (1979). MOIRA, Model of International Relations in Agriculture. Report of the Project Group, Food for a Doubling World Population, Amsterdam.

[22] Masini, F.B. and J.M. Vasquez (2000), "Scenarios as Seen from a Human and Social Perspective", Technological Forecasting and Social Change, Vol. 65, pp. 49-66.

[23] Millet, S.M. (2003), The Future of Scenarios: Challenges and Opportunities. In: Strategy \& Leadership. 31(2): 16-24.

[24] Ngwira, A., Aune, J., Thierfelder, C. (2014). DSSAT modeling of conservation agriculture maize response to climate change in Malawi. Soil and Tillage Research 143:85-94.

[25] Parry M.L., Rosenzweig, C., Igiesias, A., Livermore, M. and Fischer, G. (2004). Effects of Climate Change on Global food production under SRES emissions and Socio-economic Scenarios. Global Environmental Change, 14: 53-67.

[26] Ringland, G. (1998). Scenario Planning. John Wiley \& Sons, Chichester.

[27] Robinson, J. (1990), "Future under Glass: A Recipe for People who Hate to Predict", Futures, Vol. 22(8), pp. 820-842.

[28] Schoemaker, P.J.H. (1995), Scenario Planning. A Tool for Strategic Thinking. In: Sloan Management Review 37 92): 25-40.

[29] Schwartz, P. (1996). The Art of the Long View. Planning for the Future in an Uncertain World. New York: Doubleday Publishing.

[30] Shell International (2003), Scenarios: An Explorer's Guide. London: Shell.

[31] Van der Heijden.(2005). Scenarios: The Art of Strategic Conversation. ( $2^{\text {nd }}$ ed.). Chichester: John Wiley \& Sons.

[32] Sivakumar, M.V.K. and Glinni, A.F. 2002. Application of crop growth models in the semi-arid regions. Page 177-205.

[33] Stephens, W., and Middleton, T., (2002). Tools to Support Operational decision making. CropSoil Simulation models: Applications in developing countries. CABI International, Wallingford, USA. pp105-225.

[34] Stoll, H., King, G., Zeng, L., 2006. "WhatIf: Software for Evaluating Counterfactuals", Journal of Statistical Software, 2006.

[35] Torsten W., Philip M, and Stephan S., (2010), A Scenario based Approach to Strategic
Planning-integrating Planning and process perspective of Strategy. Leipzig Graduate School of Management, Working Paper No. 98.

[36] Tsuji GY, Uehara G, Balas S (1994). DSSAT: a decision support system for agrotechnology transfer. Version 3. Vols. 1, 2 and 3. University of Hawaii, Honolulu, HI.

[37] Var der Berg and Smith, M.T. (2005). Crop Growth Models for Decision Support in the South African Sugarcane Industry. Proc s Afr Sug Technol Ass (2005) 79: p495.

[38] Van der Heijden, K. (2002). The sixth Sense: Accelerating Organizational Learning with Scenarios, Wiley \& Sons, Chichester.

[39] Van Notten, Ph. W. F. (2000). "Create the Future: 21-22 June Workshop Report", ICIS, Maastricht.

[40] Van Notten, Ph. W. F. (2005), "Writing on the Wall: Scenario Development in Times of Discontinuity", Dissertation.

[41] Wack, P. (1985), Scenarios: Uncharted waters ahead. In: Harvard Business Review, 63(5): 73- 89.

[42] Wilson, I. (2000), "From Scenario Thinking to StrategicAction",Technological

Forecasting \& Social Change, Vol. 65, pp. 2329. 